\title{
Psychoeducation of preventive action against bullying behavior in MIN 1 Blitar
}

\author{
Istiqomah ${ }^{a, 1,}{ }^{*}$, Diana Savitri Hidayati ${ }^{a, 2}$ \\ ${ }^{a}$ Faculty of Psychology, Universitas Muhammadiyah Malang, Jl. Raya Tlogomas 246 Malang, East Java, East Java 65144 Indonesia \\ ${ }^{1}$ istiqomah@umm.ac.id, ${ }^{2}$ dianasavitri@umm.ac.id \\ * Corresponding author
}

\begin{tabular}{|c|c|}
\hline ARTICLE INFO & ABSTRACT \\
\hline $\begin{array}{l}\text { Article history } \\
\text { Received: } 2020-05-26 \\
\text { Revised: } 2020-10-21 \\
\text { Accepted: 2020-12-15 } \\
\text { Published: 2020-12-29 } \\
\text { Keywords } \\
\text { Bullying } \\
\text { Preventive } \\
\text { Psychoeducation }\end{array}$ & $\begin{array}{l}\text { Bullying in schools is one or a factor that becomes a problem / obstacle in achieving the Sustainable } \\
\text { Development Goals (SDGs), so that campaigns and enlightenment to the public about the various } \\
\text { impacts and efforts to overcome bullying must be encouraged. In this regard, this article aims to } \\
\text { describe the preventive action psychoeducation service activities against bullying behavior at MIN } 1 \\
\text { Blitar. Community service participants are Teachers and Parents of Students of MIN } 1 \text { Blitar. The } \\
\text { target of this community service is that teachers and parents at MIN } 1 \text { Blitar are able to understand } \\
\text { the condition of students or their children so that they are not prone to becoming victims of bullying } \\
\text { or becoming perpetrators of bullying, creating a Peaceful school. The method used is to provide a } \\
\text { scale of Bullying, psychoeducation and focus group discussion (FGD) to teachers and parents of } \\
\text { students of MIN } 1 \text { Blitar. Based on the post-test results of the fifth-grade students of MIN } 1 \text { Blitar, it } \\
\text { is known that } 6.5 \% \text { were identified as bullying perpetrators while 15\% were identified as victims of } \\
\text { bullying. This service activity is carried out in several forms, namely psychoeducation, FGD and self- } \\
\text { help groups, which are preventive measures of psychoeducation against bullying behavior. } \\
\text { This is an open access article under the CC-BY-SA license }\end{array}$ \\
\hline D) Check for updates & (c) (i) (อ) \\
\hline
\end{tabular}

How to cite: Istiqomah, I. \& Hidayati, D. S. (2020). Psychoeducation of preventive action against bullying behavior in MIN 1 Blitar. Journal of Community Service and Empowerment, 1(3), 128-133. doi: https://doi.org/10.22219/jcse.v1i3.12307

\section{PENDAHULUAN}

Sustainable Development Goals (SDGs), mengakui anak sebagai agen perubahan (agent of change) dan penerus (torch-bearer) bagi pembangunan berkelanjutan. Sejauh mana anak dapat berkembang - dari sisi kesehatan dan gizi, kesejahteraan dan pendidikan, serta lingkungan tempat mereka tumbuh - merupakan beberapa faktor penentu masa depan Indonesia. Beberapa topik di SDGs yang berkaitan dengan anak, yaitu kemiskinan (topik SDG 1) merupakan faktor risiko bagi perkembangan anak dan turut menyebabkan hasil di bawah rata-rata dalam kaitan dengan pangan dan gizi (SDG 2), kesehatan (SDG 3), pendidikan (SDG 4), pernikahan usia anak (SDG 5), air dan sanitasi layak (SDG 6), dan pencatatan kelahiran (SDG 16) (BAPPENAS \& UNICEF, 2017). Salah satu issue yang perlu untuk dicermati dalam dunia pendidikan adalah perisakan atau bullying. Bullying di sekolah merupakan salah satu atau faktor yang menjadi kendala/kendala dalam pencapaian SDGs (Challenger Limited, 2019; UNESCO, 2017a, 2017b).

Bullying didefinisikan sebagai tindakan agresi yang berulang-ulang di mana seseorang (atau sekelompok orang) dengan sengaja melukai seseorang secara fisik, verbal, atau psikologis. Selanjutnya, itu terjadi secara teratur dari waktu ke waktu, disengaja, dan melibatkan ketidakseimbangan kekuatan di antara keduanya (Pan et al., 2017). Bullying terjadi dalam berbagai konteks, terutama ketika pengawasan orang dewasa rendah (Bjereld et al., 2019; Monks et al., 2016; Shetgiri, 2013; Stuart-cassel et al., 2013; Swearer \& Hymel, 2015). Bullying dapat terjadi secara langsung (berhadapan) maupun melalui media sosial (Forssell, 2016; Keating et al., 2020; Nilan et al., 2015). 
Fenomena bullying di kalangan siswa di sekolah seperti fenomena gunung es (Darmawan, 2017; Nastiti et al., 2019; Octavia et al., 2020; Putri \& Budiman, 2019). Fenomena ini sering terjadi namun seperti menjadi rahasia umum yang diketahui banyak pihak di sekolah tersebut baik siswa sebagai korban, pada siswa sebagai pelaku, siswa sebagai penonton dan juga guru (Nasir, 2018; Ningrum et al., 2016; Sucipto, 2012). Di sisi lain, fenomena ini sangat negatif akibatnya baik bagi siswa yang menjadi korban maupun siswa yang menjadi penonton bahkan siswa yang menjadi pelaku sekalipun. Perilaku bullying bisa menjadi bumerang yang harus segera diputus rantainya agar tidak menimbulkan konsekuensi negatif bagi ketiga peran dalam perilaku bullying yang telah disebut-sebut sebelumnya maupun bagi lingkungan di sekitarnya (Hidayati, 2012; Levianti, 2008; Simbolon, 2013; Tristanti et al., 2020; Yusuf \& Fahrudin, 2012). Kampanye dan pencerahan kepada masyarakat tentang berbagai dampak dan upaya penanggulangan bullying harus terus digalakkan.

Berdasarkan survey awal di lapangan, perilaku bullying tersebut masih kurang dipahami oleh siswa, guru maupun orang tua siswa. Oleh karena itu diperlukan sebuah perlakuan untuk memberi pemahaman tentang hal-hal seputar perilaku bullying. Hasil penelitian yang dilakukan oleh pengabdi di MIN 1 Blitar pada siswa kelas 5 menunjukkan bahwa siswa yang terindikasi ada kencenderungan menjadi pelaku bullying sebanyak 10 siswa (12,5\%) dan siswa yang menjadi korban bullying sebanyak 24 siswa dari 80 siswa yang diteliti 30\% (Istiqomah \& Hidayati, 2019). Dengan kondisi seperti ini maka di perlukan intervensi pada siswa sekolah dasar yang memiliki kecenderungan menjadi pelaku atau korban bullying. Sejalan penelitian yang dilakukan di Cina penelitian tentang bullying dilakukan pada siswa kelas 4,5 dan 6 sekolah dasar terdapat (1) di tiga titik waktu, siswa dapat diklasifikasikan ke dalam empat kelas: pengganggu, korban, korban bully, dan anak-anak yang tidak terlibat; dan (2) siswa di kelas yang tidak terlibat cenderung tetap di kelas itu ketika pindah ke kelas yang lebih tinggi, siswa di kelas pengganggu dan korban cenderung beralih ke kelas yang tidak terlibat, sementara siswa di kelas pelaku intimidasi cenderung beralih ke kelas pelaku intimidasi. Dengan demikian, intervensi di masa depan harus diimplementasikan untuk mencegah korban bully dari perilaku bullying (Pan et al., 2017).

Bullying memberikan dampak yang buruk bagi siswa (Al-Saadoon et al., 2014; Houbre et al., 2006; Jan \& Husain, 2015; Oliveira et al., 2018; Van Werf, 2014). Siswa yang menjadi korban bullying akan memiliki kesejahteraan psikologis yang rendah, penyesuaian sosial yangng rendah tekanan psikologis yang cukup tinggi serta mengakibatkan menurunnya tingkat kesehatan siswa (Rigby, 2003). Salah satu cara untuk meningkatkan pemahaman seseorang yaitu dengan membuka diri terhadap pengetahuan yang berkembang, caranya bisa dengan bergabung di dalam suatu kelompok. Hal ini dikarenakan dalam suatu kelompok memberikan suatu manfaat bagi anggota yang berada di dalamnya, seperti kelompok sebagai sumber informasi tentang banyak hal. Manfaat ini sama halnya yang diungkapkan Sarwono dan Meinarno (2009) bahwa manfaat dari suatu kelompok antara lain: 1) Memenuhi kebutuhan individu untuk merasa berarti dan dimiliki, 2) Sebagai sumber identitas diri, dan 3) dan Sebagai salah satu sumber untuk mendapatkan informasi tentang banyak hal.

Permasalahan mitra (MIN 1 Blitar) yang ditemui adalah: (1) Kurangnya pemahaman tentang tindakan bullying disekolah baik guru maupun orang tua siswa itu sendiri. (2) Tidak ada fasilitas untuk mengupayakan mengidentifikasi siwa yang rawan mendapat perlakuan bullying maupun rawan menjadi pelaku bullying. (3) Kurangnya pendampingan siswa yang mengalami korban bullying. (4) Kurang nyamannya kondisi sekolah akibat fenomena gunung es tentang perilaku bullying. Tindakan yang dilakukan dalam pengabdian masyarakat ini adalah (1) Memberikan pengetahuan dan pemahaman tentang perilaku bullying di sekolah kepada guru dan orang tua siswa melalui kegiatan Psikoedukasi, dan (2) Mengidentifikasi siswa yang rawan mendapat perlakuan bullying maupun yang rawan menjadi pelaku bullying yang diawali dengan penyusunan instrumen untuk mengukur kecenderungan siswa menjadi pelaku bullying dan juga menyusun instrumen untuk mengukur kecenderungan siswa mengalami perilaku bullying.

Pengabdian masyarakat ini bertujuan untuk (1) Memberikan pengetahuan dan pemahaman tentang perilaku bullying; dan (2) Memberikan psikoedukasi tentang kewaspadaan terhadap siswa yang rawan menjadi korban bullying maupun rawan menjadi pelaku Bullying. Dengan demikian, artikel ini bertujuan untuk mendeskripsikan tindakan pencegahan kegiatan pelayanan psikoedukasi terhadap perilaku bullying di MIN 1 Blitar. Sejalan dengan itu, dampak dan kontribusi yang diharapkan dari pelaksanaan proram pengabdian ini adalah (1) Pemahaman guru dan orang tua siswa tentang perilaku bullying, (2) Kemampuan dalam memahami siswa atau peserta didik yang rawan menjadi korban bullying maupun menjadi pelaku bullying, (3) Pelaksanaan pendampingan bagi siswa yang merupakan korban bullying, dan (4) Terciptanya peaceful school.

\section{METODE}

Progam pengabdian masyarakat ini diorientasikan untuk mengidentifikasi siswa yang rawan menjadi korban bullying maupun rawan menjadi pelaku bullying dan menciptakan peaceful school. Adapun metode yang dilakukan yaitu dengan menyusun instrumen untuk mengidentifikasi kecenderungan siswa menjadi pelaku bullying dan instrumen untuk mengukur kecenderungan siswa untuk menjadi korban bullying, melaksanakan kegiatan psikoedukasi dan focus group discussion (FGD) untuk membentuk self-help group. Adapun pelaksanaan kegiatan, yaitu (1) Memberikan skala kecenderungan perilaku bullying, (2) Identifikasi Masalah, wawancara, (3) Memberikan skala bullying kepada siswa, (4) 
Melaksanakan Psikoedukasi, dan (5) Menyerahkan hasil skala gaya belajar ke pihak sekolah sekaligus mendiskusikan hasilnya dalam kegiatan FGD.

\section{Melakukan Psikoedukasi}

Psikoedukasi merupakan suatu kegiatan pemberian pendidikan secara psikologis kepada kelompok yang menjadi sasaran dalam progam pengabdian masyarakat ini. Teknik pelaksanaan yang dilakukan dalam psikoedukasi adalah dengan memberikan motivasi dan pemahaman serta penggalian potensi diri dengan metode ceramah dan diskusi interaktif. Dari diskusi interaktif ini maka terkuak juga permasalahan-permasalahan yang menyebabkan mereka kurang memiliki motivasi untuk berprestasi dimana permasalahan ini sangat komplek dan terkait satu dengan yang lainnya.

\section{Melaksanakan Focus Group Discussion}

FGD bertujuan untuk mendiskusikan hasil identifikasi kecenderunagn siswa menjadi Pelaku bullying dan Korban Bullying sekaligus bentuk penanganan terhadap kondisi tersebut. Bentuk penanganaan diarahkan ke pendampingan siswa baik oleh siswa yang sering disebut sebagai peer group, pendampingan oleh guru yang tentu melibatkan orang tua. Akhir dari kegiatan ini diharapakan bisa membentuk Self Help Group sebagai sebuah kelompok yang mampu memberikan pendampingan kepada siswa korban bullying.

\section{HASIL DAN PEMBAHASAN}

Hasil dari pelaksanaan pengabdian masyarakat ditunjukkan dengan Post-test terhadap 80 siswa kelas lima dengan menggunakan dua alat ukur berupa skala. Masing-masing skala bertujuan untuk (1). mengukur kecenderungan sebagai pelaku bullying dan (2). Mengukur kecenderungan sebagai korban bullying. Berdasarkan hasil post-test dapat dideskripsikan bahwa dari 80 siswa terdapat 5 siswa yang teridentifikasi sebagai pelaku bullying, dengan persentase sebesar 6,5\%. Selain itu ada 12 siswa yang teridentifikasi sebagai korban bullying sebesar 15\%. Dengan hasil post-test ini menunjukkan bahwa adanya penurunan perilaku bullying pada siswa. Banyak faktor yang membuat seorang anak mampu berpikir dan berperilaku menindas teman-temannya. Siswa hanya ikut-ikutan, takut jadi korban atau karena memang berkembang jadi pribadi yang egois karena ada perasaan dendam terhadap orang lain yang selama ini telah menindasnya. Hasil penelitian Hansen et al (2014) menunjukkan bahwa pelaku bullying disekolah ddisebabkan karena berkurangnya kesejahterann psikologis di sekolah.

Intimidasi dan viktimisasi dikaitkan dengan sejumlah kesulitan penyesuaian dalam masa kecil dan remaja (L Arseneault et al., 2010; Louise Arseneault, 2018; Fanti \& Georgiou, 2013; Garandeau et al., 2016; Guerra et al., 2011; Hong et al., 2019; Mcdougall \& Vaillancourt, 2015; Moore et al., 2017; Scholte et al., 2007). Pan et al (2017) menyatakan bahwa siswa yang menjadi korban mungkin menderita berbagai masalah psikosomatik (misalnya, tingkat kecemasan yang tinggi), kesulitan akademis (berkurangnya kinerja Akademik) dan masalah kesehatan, penelitian menunjukkan bahwa pelaku intimidasi juga menghadapi sejumlah kesulitan penyesuaian. Dengan demikian, kelompok siswa yang unik yang menggertak orang lain dan diintimidasi oleh orang lain (bully victims) mungkin menghadapi kesulitan majemuk. Hasil penelitian telah menunjukkan kecemasan, depresi, dan gejala psikosomatik sama-sama umum di kalangan pelaku intimidasi dan korban, dan sebagian besar umum di kalangan korban bully. Penindasan jelas merupakan fenomena yang berdampak negatif anak-anak dan memerlukan perhatian penelitian.

\section{Psikoedukasi kepada Orang Tua Siswa}

Psikoedukasi merupakan suatu kegiatan pemberian pendidikan secara psikologis kepada kelompok yang menjadi sasaran dalam progam pengabdian masyarakat ini. Teknik pelaksanaan yang dilakukan dalam psikoedukasi adalah dengan memberikan psiko game dan pemahaman tentang Bullying dengan metode ceramah dan diskusi interaktif. Ceramah dalam kegiatan Psikoedukasi ini dilaksanakan oleh Ibu Istiqomah, M.Si, dimana materinya berupa pengertian tentang bullying, siapa saja yang berperan dalam kasus bullying (pelaku, korban dan penonton), bagaimana ciri-ciri masing peran tersebut serta cara untuk menanganinya. Sementara diskusi interaktif dipimpin oleh Ibu Diana Savitri Hidayati, M.Psi., dimana diskusi interaktif akhirnya berkembang menjadi semacam kegiatan konsultasi kelompok karena banyak sekali orang tua yang hadir menceritakan tentang permasalahan putra-putrinya yang menjadi korban bullying.

Berbagai strategi atau intervensi dapat dipertimbangkan untuk mengurangi peluang anak lebih lanjut keterlibatan dalam intimidasi yang dapat memperburuk kondisi tersebut (Menesini \& Salmivalli, 2017; Rigby, 2020; Rivara \& Le Menestrel, 2016; Smith et al., 2019). Ini termasuk membantu korban anak-anak untuk mengembangkan keterampilan sikap asertif yang melindungi diri dan bekerja secara terapi dengan pelaku intimidasi-membuat anak-anak untuk membangun kesadaran yang lebih besar tentang konsekuensi perilaku antisosial mereka (Rigby, 2003).

\section{Pelaksanaan Focus Grup Discussion}

Pelaksanaan FGD dilaksanakan dengan tujuan untuk: (1) mensosialisaikan kepada pihak orang tua dan guru tentang hasil identifikasi terhadap siswa dan juga (2) menjaring informasi tentang bagaimana model penanganan terhadap peran- 
peran dalam kasus bullying yang selama ini telah dilaksanakan baik oleh pihak sekolah maupun orang tua. Pada pelaksanaan FGD ini pelaksana pengabdian tidak berhasil melibatkan siswa dalam kegiatan ini karena, kendala perbedaan jangkauan pemahaman antara siswa yang memang masih dalam tahap anak-anak dengan orang tua maupun guru sebagai orang tua mereka.

Pada akhir kegiatan FGD ini disepakati bahwa perlu dibentuk sebuah kelompok yang akan rutin berdiskusi serta aktif memberikan pendampingan dalam rangka pencegahan munculnya kembali perilaku bullying di kalangan siswa dan serta pendampingan untuk menangani siswa yang sudah terlanjur menjadi korban bullying. Kesepaktan lainnya adalah bahwa kelompok pendampingan tersebut awalnya hanya akan terdiri dari orang tua dan guru, namun lambat laun akan melibatkan siswa sebagai semacam "Satgas" pencegahan perilaku bullying.

\section{Pembentukan Self-Help Group}

Berdasarkan hasil FGD, maka dianggap perlu untuk membentuk self-help group, dengan dua tujuan utama yaitu pencegahan terjadinya perilaku bullying dan pendampingan untuk korban bullying. Self-help group dirasa penting untuk proses pembentukan peaceful school yang dilaksanakan secara mandiri oleh pihak-pihak yang terlibat di sekolah, yaitu siswa, orang tua, dan guru.

Bullying di sekolah merupakan masalah serius yang menimpa para korban dalam kehidupan sehari-hari di sekolah. Kelompok pendukung (Support group/self-help group) dapat membantu korban bullying untuk mengatasi status korbannya dan untuk mengetahui apa artinya menjadi anggota kelompok pendukung (Kvarme et al., 2016). Self-help group merupakan suatu kelompok atau peer dimana saling tiap anggota berbagi masalah baik fisik maupun emosional atau issue tertentu (Utami, 2008).

Rencana pelaksanaan self-help group nantinya akan dilaksanakan rutin sebulan sekali di sekolah. Selama ini acara pertemuan rutin bulanan hanya dilaksanakan secara informal oleh orang tua sebagai ajang silahturahmi antar orang tua. Dengan terbentuknya self-help group ini diharapkan pertemuan rutin bulanan oleh orangtua dapat mempunyai manfaat lain yaitu sebagai awal terbentuknya peaceful school.

\section{KESIMPULAN}

Berdasarkan hasil post-test terhadap siswa kelas lima MIN 1 Kota Blitar diketahui bahwa 6,5\% teridentifikasi sebagai pelaku bullying sementara $15 \%$ yang lain teridentifikasi sebagai korban bullying. Kegiatan pengabdian ini dilaksanakan dalam beberapa bentuk kegiatan, yaitu psikoedukasi, FGD dan self-help group, yang merupakan upaya psikoedukasi tindakan preventif terhadap perilaku bullying. Saran yang dapat bisa kami berikan terkait dengan pelaksanaan progam pengabdian ini adalah (1) Bagi orang tua dan guru diharapkan untuk dapat bekerja sama untuk terus melaksankan pertemuan secara rutin dalam rangka self-help group untuk pendampingan siswa dan pencegahan munculnya perilaku bullying di sekolah; dan (2) Bagi pihak sekolah secara luas, diharapkan mendukung kegiatan self-help group ini demi terciptanya peaceful school.

\section{UCAPAN TERIMA KASIH}

Terima kasih kami sampaikan kepada pimpinan Universitas Muhammadiyah Malang dan Dekanat Fakultas Psikologi Universitas Muhammadiyah Malang yang telah mendukung kegiatan pengabdian ini, baik secara moril maupun materiil. Terima kasih pula kami sampaikan kepada Kepala Sekolah, guru, siswa, dan wali murid/orang tua siswa MIN 1 Kota Blitar yang berkenan menjadi mitra pengabdian ini.

\section{REFERENSI}

Al-Saadoon, M., Al-Farsi, Y. M., Rizvi, S., Al-Sharbati, M., Al-Jabri, A., Almamari, S., Al-Baluki, W., \& Al-Adawi, S. (2014). The magnitude and impact of bullying among school pupils in Muscat, Oman: A cross-sectional study. Scientific World Journal, 2014. https://doi.org/10.1155/2014/169737

Arseneault, L, Bowes, L., \& Shakoor, S. (2010). Bullying victimization in youths and mental health problems: 'Much ado about nothing'? Psychological Medicine, 40(5), 717-729. https://doi.org/10.1017/S0033291709991383

Arseneault, Louise. (2018). Annual research review: The persistent and pervasive impact of being bullied in childhood and adolescence: implications for policy and practice. Journal of Child Psychology and Psychiatry and Allied Disciplines, 59(4), 405421. https://doi.org/10.1111/jcpp.12841

BAPPENAS, \& UNICEF. (2017). Laporan Baseline SDG tentang Anak-Anak di Indonesia. Kementerian Perencanaan Pembangunan Nasional (Bappenas) dan United Nations Children's Fund.

Bjereld, Y., Daneback, K., \& Mishna, F. (2019). Adults' responses to bullying: the victimized youth's perspectives. Research Papers in Education, 00(00), 1-18. https://doi.org/10.1080/02671522.2019.1646793

Challenger Limited. (2019). 2019 Sustainability Report. Challenger Limited, XV(2), 80-85.

Darmawan, D. (2017). Fenomena bullying (perisakan) di lingkungan sekolah. Jurnal Kependidikan, 1(2), $253-262$.

Fanti, K. a, \& Georgiou, S. N. (2013). Bullying, victimization, school performance, and mother-child relationship quality: Direct and 
transactional associations. Journal OfCriminology, 2013(289689), 1-11. https://doi.org/10.1155/2013/289689

Forssell, R. (2016). Exploring cyberbullying and face-to-face bullying in working life - Prevalence, targets and expressions. Computers in Human Behavior, 58, 454-460. https://doi.org/10.1016/j.chb.2016.01.003

Garandeau, C. F., Lee, I. A., \& Salmivalli, C. (2016). Decreases in the proportion of bullying victims in the classroom: Effects on the adjustment of remaining victims. International Journal of Behavioral Development, 42(1), 64-72. https://doi.org/10.1177/0165025416667492

Guerra, N. G., Williams, K. R., \& Sadek, S. (2011). Understanding bullying and victimization during childhood and adolescence: A mixed methods study. Child Development, 82(1), 295-310. https://doi.org/10.1111/j.1467-8624.2010.01556.x

Hansen, H. H., Hasselgård, C. E., Undheim, A. M., \& Indredavik, M. S. (2014). Bullying behaviour among Norwegian adolescents: Psychiatric diagnoses and school well-being in a clinical sample. Nordic Journal of Psychiatry, 68(5), 355-361. https://doi.org/10.3109/08039488.2013.845689

Hidayati, N. (2012). Bullying pada anak: Analisis dan alternatif solusi. Jurnal Insan, 14(1), 41-48. http://www.journal.unair.ac.id/filerPDF/artikel 5-14-1.pdf

Hong, J. S., Espelage, D. L., \& Rose, C. A. (2019). Bullying, peer victimization, and child and adolescent health: An introduction to the special issue. Journal of Child and Family Studies, 28(9), 2329-2334. https://doi.org/10.1007/s10826-019-01502-9

Houbre, B., Tarquinio, C., Thuillier, I., \& Hergott, E. (2006). Bullying among students and its consequences on health. European Journal of Psychology of Education, 21(2), 183-208. https://doi.org/10.1007/BF03173576

Istiqomah, I., \& Hidayati, D. S. (2019). Perbedaan psychological well being pada pelaku dan korban bullying.

Jan, A., \& Husain, S. (2015). Bullying in elementary schools: Its causes and effects on students. Journal of Education and Practice, 6(19), 43-57.

Keating, S., Mazzone, A., Milosevic, T., \& Norman, J. O. (2020). School Bullying with specific reference to cyberbullying and internet security during Covid-19 (Issue 14). The National Anti-Bullying Research and Resource Centre (ABC).

Kvarme, L. G., Aabø, L. S., \& Sæteren, B. (2016). From victim to taking control: Support group for bullied schoolchildren. The Journal of School Nursing, 32(2), 112-119. https://doi.org/10.1177/1059840515590608

Levianti, L. (2008). Konformitas dan Bullying pada Siswa. Jurnal Psikologi, 6(1), 1.

Mcdougall, P., \& Vaillancourt, T. (2015). Long-term adult outcomes of peer victimization in childhood and adolescence. American Psychologist, 70(4), 300-310.

Menesini, E., \& Salmivalli, C. (2017). Bullying in schools: the state of knowledge and effective interventions. Psychology, Health and Medicine, 22, 240-253. https://doi.org/10.1080/13548506.2017.1279740

Monks, C. P., Mahdavi, J., \& Rix, K. (2016). The emergence of cyberbullying in childhood: Parent and teacher perspectives. Psicologia Educativa, 22(1), 39-48. https://doi.org/10.1016/j.pse.2016.02.002

Moore, S. E., Norman, R. E., Suetani, S., Thomas, H. J., Sly, P. D., \& Scott, J. G. (2017). Consequences of bullying victimization in childhood and adolescence: A systematic review and meta-analysis. World Journal of Psychiatry, 7(1), 60. https://doi.org/10.5498/wjp.v7.i1.60

Nasir, A. (2018). Konseling behavioral: Solusi alternatif mengatasi bullying anak di sekolah. KONSELING EDUKASI "Journal of Guidance and Counseling," 2(1), 67-82. https://doi.org/10.21043/konseling.v2i2.4466

Nastiti, F. E., Prastyanti, R. A., \& Srirahayu, A. (2019). Advokasi UU ITE: Peningkatan kewaspadaan guru terhadap serangan cyberbullying antar peserta didik di gugus II Harjuno (Pengabdian masyarakat pada gugus II Harjuno Surakarta). Jurnal INFORMA Politeknik Indonusa Surakarta, 5(3), 6-10. http://informa.poltekindonusa.ac.id/index.php/informa/article/view/134

Nilan, P., Burgess, H., Hobbs, M., Threadgold, S., \& Alexander, W. (2015). Youth, social media, and cyberbullying among Australian youth: "Sick Friends." Social Media and Society, 1(2), 1-12. https://doi.org/10.1177/2056305115604848

Ningrum, A. W., Christiana, E., Nursalim, M., \& Lukitaningsih, R. (2016). Studi tentang perilaku bullying di sekolah menengah pertama Se-Kecamatan Prajurit Kulon Kota Mojokerto serta penanganan oleh guru BK. Jurnal BK UNESA, 6(1), 1-8.

Octavia, D., Puspita, M., \& Yan, L. S. (2020). Fenomena perilaku bullying pada anak di tingkat Sekolah Dasar. Riset Informasi Kesehatan, 9(1), 43. https://doi.org/10.30644/rik.v9i1.273

Oliveira, F. R., de Menezes, T. A., Irffi, G., \& Oliveira, G. R. (2018). Bullying effect on student's performance. EconomiA, 19(1), 57-73. https://doi.org/10.1016/j.econ.2017.10.001

Pan, Y., Liu, H., Lau, P., \& Luo, F. (2017). A latent transition analysis of bullying and victimization in Chinese primary school students. PLOS ONE, 12(8), 1-15. https://doi.org/10.1371/journal.pone.0182802

Putri, A. D. S., \& Budiman, M. A. (2019). Bullying analysis in SDN Pandean Lamper 02 Kota Semarang. 4th National Seminar on Educational Innovation (SNIP 2019), 2(1), $226-231$.

Rigby, K. (2003). Consequences of Bullying in Schools. Canadian Journal of Psychiatry, 48(9), 583-590. https://doi.org/10.1177/070674370304800904

Rigby, K. (2020). How teachers deal with cases of bullying at school: What victims say. International Journal of Environmental Research and Public Health, 17(7). https://doi.org/10.3390/ijerph17072338

Rivara, F., \& Le Menestrel, S. (2016). Preventing bullying through science, policy, and practice. In Preventing Bullying Through Science, Policy, and Practice. https://doi.org/10.17226/23482

Sarwono, S. W., \& Meinarno, E. A. (2009). Psikologi sosial. Salemba.

Scholte, R. H. J., Engels, R. C. M. E., Overbeek, G., De Kemp, R. A. T., \& Haselager, G. J. T. (2007). Stability in bullying and victimization and its association with social adjustment in childhood and adolescence. Journal of Abnormal Child Psychology, 35(2), 217228. https://doi.org/10.1007/s10802-006-9074-3

Shetgiri, R. (2013). Bullying and victimization among children. Advances in Pediatrics, 60(1), 33-51. https://doi.org/10.1016/j.yapd.2013.04.004

Simbolon, M. (2013). Perilaku bullying pada mahasiswa berasrama. Jurnal Psikologi, 39(2), 233-243. 
https://doi.org/10.22146/jpsi.6989

Smith, P. K., Bauman, S., \& Wong, D. (2019). Interventions to Reduce Bullying and Cyberbullying. In Interventions to Reduce Bullying and Cyberbullying. https://doi.org/10.3390/books978-3-03921-360-3

Stuart-cassel, V., Terzian, M., \& Bradshaw, C. (2013). Social bullying: Correlates, consequences, and prevention. Safe Supportive Learning, In Brief(May), 1-13.

Sucipto, S. (2012). Bullying dan upaya meminimalisasikannya. Psikopedagogia, 1(1), 1-12.

Swearer, S. M., \& Hymel, S. (2015). Understanding the psychology of bullying: Moving toward a social-ecological diathesis-stress model. American Psychologist, 70(4), 344-353. https://doi.org/10.1037/a0038929

Tristanti, I., Nisak, A. Z., \& Azizah, N. (2020). Bullying dan efeknya bagi siswa sekolah dasar di Kabupaten Kudus. Jurnal IImu Keperawatan Dan Kebidanan, 11(1), 1-5.

UNESCO. (2017a). Education for sustainable development goals learning objectives. UNESCO Education Sector.

UNESCO. (2017b). School violence and bullying: Global status report. International Symposium on School Violence and Bullying: From Evidence to Action, Seoul, Republic of Korea, 17 - 19 January 2017.

Utami, T. W. (2008). Pengaruh self help group terhadap kemampuan keluarga dalam merawat klien gangguan jiwa di Kelurahan Sindang Barang Bogor. Universitas Indonesia.

Van Werf, C. Der. (2014). The effects of bullying on academic achievement. Desarrollo y Sociedad, 74(2), 275-308. https://doi.org/10.13043/DYS.74.6

Yusuf, H., \& Fahrudin, A. (2012). Perilaku bullying: Asesmen multidimensi dan intervensi sosial. Jurnal Psikologi, 11(2), 1-10. https://doi.org/10.14710/jpu.11.2.10 